\title{
Knowledge on Breast Cancer and Practice of Self-Examination among Schoolgirls in Democratic Republic of the Congo
}

\author{
Badiambile Mpulumba ${ }^{1, *}$, Kalonji Mukendi ${ }^{1}$, Kasongo Musasa ${ }^{2}$, Bakenge Manongo ${ }^{1}$, Ntumba Bambi ${ }^{3}$, Kalonji Mbaya ${ }^{1}$, and \\ Mukendi Muamba ${ }^{1}$
}

${ }^{1}$ Faculty of Medicine and Public Health, Official University of Mbujimayi, Kasaï Oriental, Democratic Republic of the Congo

${ }^{2}$ Faculty of Medicine and Public Health, University of Mwene Ditu, Province of Lomami, Democratic Republic of the Congo

${ }^{3}$ Higher Institute of Arts and Crafts (ISAM), Democratic Republic of the Congo

*Corresponding author: Badiambile Mpulumba, Faculty of Medicine and Public Health, Official University of Mbujimayi, Kasaï Oriental, Democratic Republic of the Congo, Tel: (+243)894605283/(+243) 977181582; E-mail: remympulumba@gmail.com

Received: 03 Feb, 2021 | Accepted: 16 Mar, 2021 | Published: 22 Mar, 2021

Citation: Mpulumba B, Mukendi K, Musasa K, Manongo B, Bambi N, et al. (2021) Knowledge on Breast Cancer and Practice of Self-Examination among Schoolgirls in Democratic Republic of the Congo. J Epidemiol Public Health Rev 6(1): dx.doi.org/10.16966/2471-8211.207

Copyright: (c) 2021 Mpulumba B, et al. This is an open-access article distributed under the terms of the Creative Commons Attribution License, which permits unrestricted use, distribution, and reproduction in any medium, provided the original author and source are credited.

\begin{abstract}
Background: The breast cancer represents a major problem of public health in Democratic Republic of the Congo. This study aims at assessing the knowledge about breast cancer and the practice of breast self-examination among schoolgirls, and to propose effective intervention measures to promote early diagnosis and treatment of breast cancer in Mbujimayi.
\end{abstract}

Methods: This was a descriptive \& cross-sectional study conducted from December 18, 2019 to March 18, 2020 including 962 schoolgirls. Data analysis was achieved with SPSS software package, version 16.0.

Results: Schoolgirls (61.75\%) know about breast cancer; $26.72 \%$ are aware of its existence through a Medical Officer. The risk factors of breast cancer were unknown (59.56\%) and for $47.56 \%$ of schoolgirls, breast self-examination was a preventive way, whereas $61.64 \%$ did not know about breast self-examination. But $61.85 \%$ were not used to breast self-examination. The knowledge on breast cancer, the risk factors and the practice of breast self-examination were statistically linked to age with respectively P-value $=0.001 ; 0.0286$ and 0.01 . In $53.15 \%$, self-examination of the breast was performed respecting the principles and mostly in erect position (48.51\%). Breast own-examination was performed once monthly in $31 \%$, flat hand was the most used technique (54.22\%), and $56.44 \%$ of schoolgirls claimed not to feel pain during the breast palpation process.

Conclusion: According to the results, the sensibilization should be focused on knowledge, practice of breasts self-examination of an organization of screening campaigns.

Keywords: Breast cancer; Knowledge; Self-examination; Schoolgirls; DR Congo

\section{Introduction}

The breast cancer is the most frequent cancer in women worldwide, the second cause of death after the lung cancer. In Europe, 275100 new cases of breast cancer were estimated in 2012; this cancer represents the quarter of all cancers. The risk for a woman to experience the breast cancer is estimated at $8 \%$ during her expectancy. It has been proven that early diagnosis of breast cancer at an early development stage could make its management more effective, cheaper and could improve the global prognosis $[1,2]$.

The screening methods of breast cancer include self-examination, clinical breast examination, mammography and MRI. Breasts selfexamination and lymph nodes areas is known and performed by most of occidental women, it enables early diagnosis of breast cancer in $85 \%$ of cases [1-4]. The learning of this self-exam should be performed individually by a medical officer or a paramedical and the technique spread through Medias [4]. In women practicing selfexamination, the diagnosis of breast cancer is made before the extent to the lymph nodes in $2.7 \%$; the survival after treatment is of $75 \%$ up to 5 years [5-8]. In Democratic Republic of the Congo (DRC), breast cancer is the second most common cancer in Congolese women after that of the cervix. By lack of early detection and means to seek treatment, $44 \%$ of women die of breast cancer. Studies conducted by Mashinda KD, et al., demonstrated that the breast cancer was found in $13.7 \%$ in teenagers, dominated by adenofibroma [2]. However, in the Democratic Republic of the Congo few studies exist on the knowledge of breast cancer and breast self-examination in high-educated girls.

In Mbujimayi, the breast cancers are not rare. Breast selfexamination was only practiced by $1 \%$ of girls [1]; which justify the 
choice of this topic. Most of teenagers are not informed about selfexamination of breast. We asked ourselves some questions whose answers should be a step forward in the control of this phenomenon: What could be the degree of knowledge on breast cancer among schoolgirls? What are the knowledge status and practice of selfexamination of breast among those schoolgirls? Therefore, a research on the topic is of paramount importance. Henceforth, the study aims at assessing the knowledge about breast cancer and the practice of breast self-examination among schoolgirls, and to propose effective intervention measures to promote early diagnosis and treatment.

\section{Materials and Methods}

\section{Study design}

Eight schools were selected in Mbujimayi, Province of Kasaioriental, in Democratic Republic of the Congo, of which four are located in Kanshi township (Muanjadi Grammar School, Sainte Thérèse Grammar School, Bukasa Nsende College and Prince de l'Académie high school) and four in Dibindi township (Saint Clément I College, Bianka Grammar School, Eureka Kasaï IV College and Ecole de Métier high school). These schools were chosen because they are all dedicated to education of girls. To collect data, a questionnaire form was used. This was a descriptive cross-sectional study conducted from December 18, 2019 to March 18, 2020.

\section{Sample size and participants}

Considering the prevalence found by Mashinda KD, et al., [2] who demonstrated that breast cancer was present in $13,7 \%$, the sample size was calculated as follows: $\mathrm{n}=(1.96) 2 \times \mathrm{p} \times \mathrm{q} / \mathrm{d}^{2}=(1.96) 2 \times \mathrm{p} \times \mathrm{q} / \mathrm{d}^{2}$

- 1, 16 : corresponding value to confidence level of $95 \%$

- $\quad$ p: prevalence $=0.137$

- $\mathrm{q}=1-\mathrm{p}=(1-0.137)=0.863$

- $\mathrm{d}$ : degree of precision needed $=0.02$

- $\mathrm{n}=(1.96) 2 \times(0.137 \times 0.863) /(0.02) 2=1135.5$

Then the number 1136 was obtained. Some questionnaire forms (174) were discarded because they were not relevant or because they were not completely filled. Finally the sample size was constituted of 962 schoolgirls from third to sixth form of the above named high schools, who filled out completely the questionnaire. They ranged from 14 to 22 years old, because our study focused on teenagers.

\section{Study variables}

Knowledge about breast cancer: breast cancer existence awareness and knowledge acquisition source, breast cancer risk factors awareness, prevention, skills on own-examination of lymph nodes areas. Practice of breast self-examination: knowledge and skills on self-examination of breast, cycle stage and position adopted for breast self-examination, frequency of self-examination, technique performed and the feelings experienced.

\section{Data analysis}

The collected data were encoded on Excel, and then transferred to SPSS software package, version 16.0. The significance threshold was set to $\mathrm{p}<0.05$ for a confidence interval of $95 \%$. Chi-square was used to verify association between different factors.

\section{Ethical consideration}

Anonymity and respect of confidentiality of data were assured. The consent was obtained orally after the schoolgirls were informed about the purpose of the investigation.

\section{Results}

\section{Knowledge on breast cancer}

Most of schoolgirls (594) i.e., 61.75\% know about the existence of breast cancer. The source of acquisition of information on the existence of breast cancer in teenagers was mostly from Medical officer (26.72\%). More than half of schoolgirls (573) i.e., 59.56\% do not know about the existence of breast cancer risk factors. One hundred and four girls (26.74\%) among schoolgirls claimed that bearing money on the breasts in their bra could be a risk factor of breast cancer. Most of schoolgirls (573) i.e., 59.56\%, claimed not to know the prevention means of breast cancer; in $47.56 \%$ of cases, self-examination was regarded as breast cancer prevention means (Table 1).

\section{Knowledge on breast self-examination}

More than half of girls (54.89\%) did not know about self-examination of ganglionic areas; Armpit ganglionic areas were most known by girls in $47.24 \%$ of cases. The majority of girls $(61.64 \%)$ reported having not been aware of the breast self-examination practise; the majority of girls (61.85\%) were not used to actually practise breast self-examination .In $53.15 \%$, breast palpation was carried out after menstruations and the position adopted in the majority of cases was the upstation (48.51\%). One hundred and fourteen girls (31.15\%) confessed having performed breast self-palpation or examination once in a month; the breast flat

Table 1: Knowledge on breast cancer for schoolgirls in Mbujimayi.

\begin{tabular}{|c|c|c|c|}
\hline Characteristics & Category & Number & Percent(\%) \\
\hline \multirow{2}{*}{$\begin{array}{l}\text { Knowledge on the } \\
\text { existence of breast } \\
\text { Cancer }\end{array}$} & No & 594 & 61.75 \\
\hline & Yes & 368 & 38.25 \\
\hline \multirow{8}{*}{$\begin{array}{l}\text { Source of knowledge } \\
\text { acquisition on the } \\
\text { existence of breast } \\
\text { cancer }\end{array}$} & Medical officers & 159 & 26.72 \\
\hline & Parents & 138 & 23.19 \\
\hline & Radio Station & 93 & 15.63 \\
\hline & Nurse & 73 & 12.27 \\
\hline & Television & 58 & 9.75 \\
\hline & School & 43 & 7.23 \\
\hline & Internet & 28 & 4.71 \\
\hline & Church & 3 & 0.5 \\
\hline \multirow{2}{*}{$\begin{array}{l}\text { Knowledge about risk } \\
\text { factors }\end{array}$} & No & 573 & 59.56 \\
\hline & Yes & 389 & 40.44 \\
\hline \multirow{6}{*}{$\begin{array}{l}\text { Declared factor as being } \\
\text { breast cancer risk factors }\end{array}$} & $\begin{array}{l}\text { Money on the } \\
\text { breast in a bra }\end{array}$ & 104 & 26.74 \\
\hline & Cigarette & 68 & 17.48 \\
\hline & Family history & 58 & 14.91 \\
\hline & $\begin{array}{l}\text { Breast density } \\
\text { augmented }\end{array}$ & 45 & 11.57 \\
\hline & Alcohol & 44 & 11.31 \\
\hline & Others & 70 & 17.99 \\
\hline \multirow{2}{*}{$\begin{array}{l}\text { Knowledge about } \\
\text { prevention means }\end{array}$} & No & 573 & 59.56 \\
\hline & Yes & 389 & 40.44 \\
\hline \multirow{3}{*}{$\begin{array}{l}\text { Knowledge about breast } \\
\text { cancer prevention means }\end{array}$} & Self-examination & 185 & 47.56 \\
\hline & Screening & 157 & 40.36 \\
\hline & $\begin{array}{l}\text { Genetic material } \\
\text { examination }\end{array}$ & 47 & 12.08 \\
\hline
\end{tabular}

Citation: Mpulumba B, Mukendi K, Musasa K, Manongo B, Bambi N, et al. (2021) Knowledge on Breast Cancer and Practice of SelfExamination among Schoolgirls in Democratic Republic of the Congo. J Epidemiol Public Health Rev 6(1): dx.doi.org/10.16966/2471- 
hand position was the most used (54.22\%) during the breast palpation process and six girls $(56.44 \%)$ confessed having not had any pain during the breast palpation or examination process (Table 2).

\section{Knowledge on breast cancer by age}

The schoolgirls of $19-22$ years old, i.e., $82.57 \%$, knew more about the existence of breast cancer than the youngest. The difference observed was statistically more significant: $\mathrm{p}<0.001$; the schoolgirls of 19 to 22 years old $(66.97 \%)$ were not so much aware of breast cancer risk factors as those ones whose age was $\leq 14$ years $(50 \%)$. The difference is statistically significant: $p=0.0286$; Seventy-six schoolgirls (69.72\%) did not know how to practise the self-examination of the breast and their age ranged from 19-22 years against 75 schoolgirls, i.e., (62.50\%), whose age was $\leq 14$ years knew about breast self-examination practise. The difference observed was statistically significant: $\mathrm{p}=0.01$ (Table 3 ).

\section{Discussion}

The breast cancer is one of the common malignant tumour in women in Democratic Republic of the Congo [8]. It arises mostly in young

Table 2: Knowledge on breast self-examination for schoolgirls in Mbujimayi.

\begin{tabular}{|c|c|c|c|}
\hline Characteristics & Category & Number & Percent(\%) \\
\hline \multirow{3}{*}{$\begin{array}{l}\text { Knowledge about } \\
\text { Ganglionic areas self- } \\
\text { examination }\end{array}$} & Non & 528 & 54.89 \\
\hline & Yes & 434 & 45.11 \\
\hline & Armpit & 205 & 47.24 \\
\hline \multirow{5}{*}{$\begin{array}{l}\text { Knowledge about } \\
\text { ganglionic areas }\end{array}$} & Sub-clavicular & 106 & 24.42 \\
\hline & $\begin{array}{l}\text { Internal mammary } \\
\text { chain }\end{array}$ & 67 & 15.44 \\
\hline & Inguinal & 27 & 6.22 \\
\hline & Cervical & 15 & 3.45 \\
\hline & Mandibular & 14 & 3.23 \\
\hline \multirow{2}{*}{$\begin{array}{l}\text { Knowledge about } \\
\text { breast self-examination } \\
\text { practise }\end{array}$} & No & 593 & 61.64 \\
\hline & Yes & 369 & 38.36 \\
\hline \multirow{2}{*}{$\begin{array}{l}\text { Real practise of breast } \\
\text { self-examination }\end{array}$} & No & 595 & 61.85 \\
\hline & Yes & 367 & 38.15 \\
\hline \multirow{3}{*}{$\begin{array}{l}\text { Menstruations cycle } \\
\text { duration of breast self- } \\
\text { examination }\end{array}$} & After the periods & 194 & 53.15 \\
\hline & In midperiods & 98 & 26.85 \\
\hline & During the periods & 73 & 20 \\
\hline \multirow{3}{*}{$\begin{array}{l}\text { Position adopted of } \\
\text { breast self-examination }\end{array}$} & Up station & 179 & 48.51 \\
\hline & Seated station & 104 & 28.18 \\
\hline & Lay down station & 86 & 23.31 \\
\hline \multirow{5}{*}{$\begin{array}{l}\text { Self-examination } \\
\text { frequency }\end{array}$} & Month & 114 & 31.15 \\
\hline & Day & 80 & 21.86 \\
\hline & Sporadic & 79 & 21.59 \\
\hline & Week & 59 & 16.12 \\
\hline & Years & 34 & 9.29 \\
\hline \multirow{2}{*}{ Technique adopted } & Flat hand approach & 199 & 54.22 \\
\hline & With fingers & 168 & 45.78 \\
\hline \multirow{2}{*}{ Experienced feeling } & Painless & 206 & 56.44 \\
\hline & Painful & 159 & 43.56 \\
\hline
\end{tabular}

Congolese women and the diagnosis is often made at advanced stages [9]. The sensitization on breast cancer awareness and the practice of screening methods enable early detection of breast cancer, improving so the survival prognosis and providing best health results [10]. This study, «assessment of knowledge on breast cancer and practice of breast own-examination among schoolgirls», had been conducted for the first time in Mbujimayi. Our study provides useful information to satisfy the lack of documentation on the topic in Democratic Republic of the Congo.

In our series $61.75 \%$ of schoolgirls are aware of the existence of breast cancer. On the other hand in the study of Darre T, et al., in Togo, female medical students in general were aware of the existence of breast cancer [11]. This low knowledge rate on breast cancer could be justified by lack of sensitization on the condition in different areas throughout the country. This study has demonstrated that the source of knowledge acquisition on the existence of breast cancer among teenagers was from Medical Officer (26.72\%) in most of cases; unlike the results reported by Alwan NAS, et al., in Iraq, the media dominated television and radio precisely [12]. The studies conducted in developed countries demonstrated that the attitude and orientation of healthcare provider are importantly decisive for utilization of screening programmes of breast cancer [10]. That could be justified by the fact that the Medical Officer seems trustworthy for everyone as concerns health issues, in relation to the Physician-Patient relationship. Nevertheless, the information disseminated on the subject by the media must be encouraged and above all presented by health workers. Fifty eight point ninety four percent of schoolgirls were aware of breast cancer. In the study of Darre T, et al., in Togo, female medical students in general had knowledge about breast cancer [11]. This is a problem linked to our environment, since other sources of information are not exploited.

Most of schoolgirls (59.56\%) did not know about the existence of breast cancer risk factors of. Twenty six seventy four percent of schoolgirls reported that bearing money on breasts was a common risk factor of breast cancer according to our findings. These results do not corroborate with those found by Darre $\mathrm{T}$, et al., in Togo which demonstrated that the answer of students to risk factors of breast cancer has been globally satisfying and the risk factors settled for the breast cancer comprised reproductive factors and hormonal (menarche, delayed menopause, nulliparous, oestrogens exogenous), the genetic, age, adiposity, alcohol consumption and meanness [11]. On the other hand, a feeble knowledge of risk factors ends often up by bad attitudes and bad behaviors concerning the maintenance of safe lifestyle and screening methods of breast cancer [13].

Therefore, it is important to reinforce the knowledge of schoolgirls so that they can better educate people about the risk factors associated with breast cancer to enable them to integrate sustainable attitudes and envisage lifestyle change. Their mastery on risk factors will depend upon the quality of information spread among people. A feeble level of knowledge and sensitization on risk factors of breast cancer seems to drag along stiffness to recognize symptoms of breast cancer, severity of disease and advanced stages of the condition owing to delay in looking out for support. The breast cancer kills silently the women, principally those one who are not aware of breast cancer and the screening methods for early detection $[11,14]$.

Our results demonstrated that more than a half of schoolgirls (59.56\%) claimed to know the prevention mean of breast cancer and in $47.56 \%$ of cases self-examination of breasts was the prevention way of breast cancer. Natural history of breast cancer is a long process, a structured program for early detection could reduce significantly the

Citation: Mpulumba B, Mukendi K, Musasa K, Manongo B, Bambi N, et al. (2021) Knowledge on Breast Cancer and Practice of SelfExamination among Schoolgirls in Democratic Republic of the Congo. J Epidemiol Public Health Rev 6(1): dx.doi.org/10.16966/2471- 
Table 3: Knowledge on breast cancer for schoolgirls in Mbujimayi by age.

\begin{tabular}{|c|c|c|c|c|c|c|}
\hline \multirow[t]{2}{*}{ Age(Years) } & \multicolumn{2}{|c|}{$\begin{array}{l}\text { Knowledge about the existence of breast } \\
\text { cancer }\end{array}$} & \multicolumn{2}{|c|}{ Knowledge of risk factors of breast cancer } & \multicolumn{2}{|c|}{$\begin{array}{l}\text { Knowledge and skills on breast self- } \\
\text { examinition }\end{array}$} \\
\hline & Yes & No & Yes & No & Yes & No \\
\hline$\leq 14$ & $72(60)$ & $48(40)$ & $60(50.00)$ & $60(50.00)$ & $75(62.50)$ & $45(37.50)$ \\
\hline $15-18$ & $432(58.94)$ & $301(41.06)$ & 293(39.97) & $440(60.03)$ & $261(35.61)$ & $472(64.39)$ \\
\hline $19-22$ & $90(82.57)$ & $19(17.43)$ & $36(33.03)$ & $73(66.97)$ & $33(30.28)$ & $76(69.72)$ \\
\hline$\chi^{2}$ & 22.6 & & 7.1065 & & 34.9376 & \\
\hline$P$ & 0.001 & & 0.0286 & & 0.01 & \\
\hline
\end{tabular}

incidence and the mortality of this condition. It is in this context that the Democratic Republic of the Congo has organized a National Plan to reinforce the prevention and monitoring of breast cancer. The objective is to reduce at $30 \%$ the mortality of this issue in the forthcoming 10 years. In this National Plan, they focus on the importance of selfexamination of the breasts [3]. Indeed, Marzouni HZ, et al., in a study on skills on self-examination of the breast in Iran reported the positive effects of sensitization in the context of prevention [15].

It is outlined from our study that more than a half of schoolgirls (54.89\%) did not know to own-examine the lymph nodes areas. Axillary lymph nodes area was the most known of all the lymph nodes areas by the schoolgirls in $47.24 \%$ of cases according to our results. In other developed countries, many studies showed that $85 \%$ of women were aware of the existence of breast conditions; most of women perform regularly self-examination of breasts and lymph nodes areas, more better, the screening program is not organized in these countries $[16,17]$.

For knowledge and skills on self-examination of breasts, $61.64 \%$ of schoolgirls claimed to be unaware of self-examination and many schoolgirls $(61.85 \%)$ did not perform self-examination in our series. contrary to Darre T, et al., [11] in Togo wherein $83.6 \%$ of schoolgirls performed a self-examination of breast and clinic check-up of breast. Although self-examination is the common used technique of early detection, evidence of its effectiveness is discussed. This technique could lead to an excessive detection of nodules by avoiding useless medical visits and expenditures related to diagnosis, that is needed in context of low-and-middle-income countries with settings and health resources limited [18].

However, even though the current data do not support the selfexamination as an approach of breast cancer screening, teaching of self-examination of the breast in the countries wherein most of women suffering from breast cancer at advanced stage can improve their knowledge on breast cancer and lead to early diagnosis [11]. The selfexamination of the breasts has the advantage of being the relatively simple and cheaper technique for early detection of breast cancer [9]. The role of self-examination of the breast is important in the regions wherein mammography could not be available for financial purpose or accessibility.

The results from bi-variable analysis between different variables: knowledge on breast cancer, awareness of risk factors and practice of self-examination of breasts were associated statistically to age with respectively (P-value $=0.001 ; 0.0286$ and 0.01 ). Contrary wise Ousmane in a study on attitude and practice of self-palpation of breast among women in Morocco demonstrated that seven variables were associated statistically to the practice of self-examination of breasts: the residence, the education, the financial status, familial and personal history of breast cancer, knowledge about breast cancer and body movement. The pertaining to different age categories had not impacted on the practice of self-examination of breasts $(p=0.182)$. The literature confirms that familial and personal history of breast cancer could impact on knowledge, risk factors of breast cancer and practice of self-examination of breasts [19].

Moreover, the statistics indicate that $90 \%$ of mammary nodules are found out by women themselves [20]. In $53.15 \%$, the breast palpation was made after menstruations and in the majority of cases the schoolgirls performed the chest palpation in a standing-up position (48.51\%) as show our results. The chest palpation was performed after the periods and this could be justified by the fact that the breasts are supple after menstruations and in the standing-up position because this position is favourable for most of them, since the self-examination of the breast is often performed during showers or in the standing-up position and in front of a mirror. Concerning the frequency of self-examination of breasts and the technique adopted, $31.15 \%$ of schoolgirls claimed having done self-examination of breasts once monthly, flat hand was the technique the most used in $54.22 \%$ during palpation of the breast and $56.44 \%$ of schoolgirls claimed not experiencing pain when performing the technique according to our results. Self-examination of the breasts well done regularly could enable woman to keep close to her body. The purpose of self-examination of the breast is to check up the change of size, shape, borders, coloration, pain or any change of skin aspect and consider as an opportunity to see a Medical Officer.

\section{Conclusion}

The breast cancer is a major problem of public health in Democratic Republic of the Congo. Most of schoolgirls know about the existence of breast cancer but the level of knowledge on risk factors, practice of selfexamination of the breasts and prevention means are not sufficient. The programme of sensitization should focus on risk factors, prevention means and organization of screening campaigns. The data outlined in this paper could be used in Education programs to improve knowledge on breast cancer at early age and teach the appropriate techniques for breast self-examination. However, further complementary studies are of paramount importance to reinforce these results.

\section{Ethical Approbation and Participation Consent}

This study has been approved and authorization has been obtained from the Dean of the Faculty of Public Health at Official University of Mbujimayi, to whom we wrote to ask for permission by explaining the objectives and methods of the study. The schoolgirls were ensured that their participation to the study was optional and anonymous. They were equally assured of confidentiality of the provided information and that all data should be analysed anonymously. A written consent form has been filled out before the participation to the interview. 


\section{Study Limitation}

This study does not deal with the chest self-examination technique; neither does it tackle the knowledge about the cancer symptoms or the cause and effect relationship. This study does not break down schoolgirls according to their school.

\section{Contribution of Authors}

Mpulumba B is responsible of conception of the study, undertook the interview, collected data, analysed and interpreted the data and wrote the draft. Mukendi K, Musasa K, Mbaya K, Bambi $\mathrm{N}$ and Manongo B participated in the conception of the study, supervised data collection and data analysis. Mukoka K participated in the correction of the grammatical mistakes herein contained in the present work after its first translation. Muamba $\mathrm{M}$ is the scientific manager of the study, data analysis and interpretation, and the preparation of the final draft.

\section{Conflict of Interest}

The authors do not claim any interest conflict.

\section{References}

1. World Health Organization (1985) L'auto-examen dans la détection précoce du cancer du sein: Mémorandum d'une Réunion de l'OMS. Bull World Health Organ 63: 495-503.

2. Mashinda KD, Kayembe KP, Mapatano MA (2012) Cancer prevalence in the Democratic Republic of the Congo: anatomopathological data collected at the University Clinics and at the General Reference Hospital of Kinshasa Cancer prevalence in Democratic Republic of the Congo: anatomopathologic. Ann Afr Med 5: 1087-1093.

3. Luyeye Mvila G, Postema S, Marchal G, Van Limbergen E, Verdonck $F$, et al. (2014) From the set-up of a screening program of breast cancer patients to the identification of the first BRCA mutation in the DR Congo. BMC Public Health 14: 759.

4. Abdelkarim B, Walid A, Abderrahmane D, El-amine YM, Mohammed $S$ (2013/2014) Etude rétrospective des cas des cancers du sein prise en charge au niveau du service de gynéco-obstétrique. Universite Abou Bekr Belkaid-Tlemcen, Algeria.

5. Lansac J, Body G, Magnin G (2011) La pratique chirurgicale en gynécologie obstétrique. Elsevier Health Sciences, France.

6. Loïc B, Vinatier D (2011) Epidemiologie Du Cancer Du Sein Service de chirurgie gynécologique et mammaire, Hôpital Jeanne de Flandre. Centre Hospitalier Régional Universitaire de Lille, France.

7. World Health Organization (2017) Breast cancer: disease prevention and control.
8. Darre T, Kpatcha TM, Bagny A, Maneh N, Gnandi-Piou F, et al. (2017) Descriptive Epidemiology of Cancers in Togo from 2009 to 2016 Asian Pac J Cancer Prev 18: 3407-3411.

9. Darré T, Tchaou M, Folligan K, Amadou A, N'Timon B, et al. (2017) Breast cancer cases of female patients under 35 years of age in Togo: A series of 158 cases. Mol Clin Oncol 7: 1125-1129.

10. Tsu VD, Jeronimo J, Anderson BO (2013) Why the time is right to tackle breast and cervical cancer in low-resource settings. Bull World Health Organ 91: 683-690.

11. Darre T, Tchaou M, Djiwa T, Tcharié EL, Brun LCV, et al. (2020) Breast Cancer: Knowledge, Attitudes on Risk Factors and Means of Screening by Medical Students from Lomé, Togo. Adv Breast Cancer Res 9: 127-137.

12. Alwan NAS, Al-Attar WM, Eliessa RA, Madfaie ZA, Tawfeeq FN (2012) Knowledge, attitude and practice regarding breast cancer and breast self-examination among a sample of the educated population in Iraq. East Mediterr Health J 18: 337-345.

13. Balekouzou A, Yin P, Pamatika CM, Bekolo CE, Nambei SW, et al. (2017) Reproductive risk factors associated with breast cancer in women in Bangui: a case-control study. BMC Womens Health 17: 14.

14. Trimble EL (2017) Breast Cancer in Sub-Saharan Africa. J Glob Oncol 3: $187-188$

15. Marzouni HZ, Lavasani Z, Shalilian M, Najibpour R, Fakhr MS, et al. (2013) Women's Awareness and Attitude Toward Breast SelfExamination in Dezful City, Iran, 2013. Iran Red Crescent Med J 17: e17829.

16. Public health recommendations (2014) Breast cancer screening in France: identification of high-risk women and screening methods. Haute Autorité de Santé, France.

17. Le Falher $\mathrm{C}$ (2015) Clinical breast examination in screening for breast cancer in women under 50 without risk factors: a systematic review of the literature. Sciences duVivant dumas-01279258.

18. Rahman SA, Al-Marzouki A, Otim M, Khayat NEHK, Yousuf R, et al. (2019) Awareness about Breast Cancer and Breast Self-Examination among Female Students at the University of Sharjah: A CrossSectional Study. Asian Pac J Cancer Prev 20: 1901-1908.

19. Ousmane D (2016-2017) Attitude et pratique de l'autopalpation du sein chez les femmes au maroc, Mémoire de fin de spécialité en Epidémiologie 23-24.

20. Sama CB, Dzekem B, Kehbila J, Ekabe CJ, Vofo B, et al. (2017) Awareness of breast cancer and breast self-examination among female undergraduate students in a higher teachers training college in Cameroon. Pan Afr Med J 28: 91. 